OPEN

SUBJECT AREAS:

ENVIRONMENTAL

CHEMISTRY

BIOGEOCHEMISTRY

Received

10 September 2013

Accepted

14 October 2013

Published

4 November 2013

Correspondence and requests for materials should be addressed to

J.S. (Schaller@forst.tudresden.de)

\section{Thunderbolt in biogeochemistry: galvanic effects of lightning as another source for metal remobilization}

\author{
Jörg Schaller' , Arndt Weiske' \& Frank Berger ${ }^{2,3}$
}

\begin{abstract}
'Institute of General Ecology and Environmental Protection, Technische Universität Dresden, PF 1117, 01737 Tharandt, Germany, ${ }^{2}$ Institute of Electrical Power and Control Technology, Ilmenau University of Technology, 98693 Ilmenau, Germany, ${ }^{3}$ VDE e.V. Committee of lightning protection and research (ABB), 60696 Frankfurt am Main, Germany.
\end{abstract}

Iron and manganese are relevant constituents of the earth's crust and both show increasing mobility when reduced by free electrons. This reduction is known to be controlled by microbial dissimilation processes. Alternative sources of free electrons in nature are cloud-to-ground lightning events with thermal and galvanic effects. Where thermal effects of lightning events are well described, less is known about the impact of galvanic lightning effects on metal mobilization. Here we show that a significant mobilization of manganese occurs due to galvanic effects of both positive and negative lightning, where iron seems to be unaffected with manganese being abundant in oxic forms in soils/sediments. A mean of $0.025 \mathrm{mmol}$ manganese (negative lightning) or $0.08 \mathrm{mmol}$ manganese (positive lightning) mobilization may occur. We suggest that lightning possibly influences biogeochemical cycles of redox sensitive elements in continental parts of the tropics/subtropics on a regional/local scale.

ron $(\mathrm{Fe})$ and manganese $(\mathrm{Mn})$ represent a major portion of the earth's crust ${ }^{1,2}$ and are inherently involved in ecosystem processes ${ }^{3}$. The mobility of both elements is controlled mainly by redox conditions (e.g. iron wheel).

Under oxic conditions $\mathrm{Fe}$ is abundant in an immobile trivalent form and $\mathrm{Mn}$ in an immobile tetravalent form where under anoxic conditions $\mathrm{Fe}$ and $\mathrm{Mn}$ are highly mobile. The reduction potential of these elements depends on the acquisition of electrons. During microbial organic matter decomposition in soils and sediments, organic matter is oxidized utilizing different electron acceptors e.g. oxygen, nitrate and sulfate ${ }^{4,5}$ as well as Fe and $\mathrm{Mn}$ oxides ${ }^{6,7}$ thus being reduced ${ }^{3}$. With the reduction of $\mathrm{Fe}^{3+}$ to $\mathrm{Fe}^{2+}$ and $\mathrm{Mn}^{4+}$ to $\mathrm{Mn}^{2+}$ the mobility of both metals increases where the metals will be mobilized and released from the sediment into the pore water. The same process occurs in the case of free electron supply. A natural source of free electrons is cloud to ground lightning including both thermal and galvanic effects ${ }^{8,9}$ influencing e.g. nitrogen fixation as an important process in biogeochemistry ${ }^{10}$. It was found that thermal effects resulting from lightning are responsible for the reduction of redox sensitive elements such as phosphorus and iron in fulgurites ${ }^{9,11}$. However, less is known about the impact of the transferred energy charge by lightning (galvanic effect) on the mobilization of redox sensitive elements. During a lightning event an electron plasma channel is formed in which an electron flow from cloud to ground will occur ${ }^{12}$. The charge transferred from cloud to ground is different for positive lightning (16 coulomb (C)) in $\sim 10 \%$ of all cases and negative lightning $(5.2 \mathrm{C})$ in $\sim 90 \%$ of all case ${ }^{13-16}$. Furthermore, the lightning activity on earth is inhomogeneously distributed being highest in the tropics (up to 70 lightning flashes per $\mathrm{km}^{2}$ and year ${ }^{17}$ ) whereas most of the ocean area remains unaffected. Hence, there are large differences in lightning activity on a regional scale. Because of the very high abundance of lightning events on earth ${ }^{18}$ the mobilization of metals by galvanic lightning effects may be an important part of global and local biogeochemical cycling of redox sensitive metals.

Consequently, the influence of galvanic effects due to lightning activity on metal remobilization on a global and regional scale was estimated here for the first time by laboratory experiments and calculations on different scales.

\section{Results}

We found a significant impact ( $\mathrm{p}<0.001$ ) of lightning on Mn mobilization from soil/sediment to the water body/ pore water comparing treatments with and without lightning (control treatment) (Fig. 1). However, no mobilization of Fe was found (always below limit of detection). The charge of lightning has a clear effect on metal mobilization. Increasing lightning charge strongly increases metal mobilization (Fig. S1). We also found an 


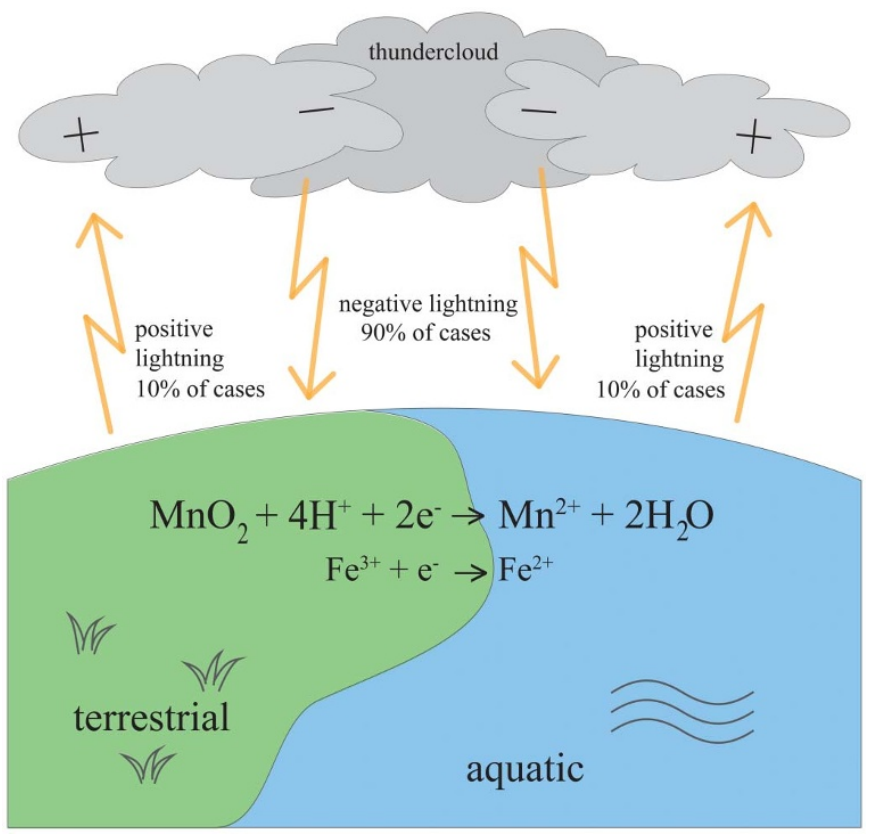

Figure $3 \mid$ Scheme of the biogeochemical processes affected by lightning activity.

on Fe/Mn mobilization/cycling can be estimated. Still the mobilization of elements even local scale $\left(\right.$ per $\left.\mathrm{km}^{-2}\right)$ is small ${ }^{3}$.

Such a mobilization of Fe/Mn (and possibly phosphorus bound to iron(III)) by galvanic lightning effects may affect the biogeochemistry of ecosystems with nutrient deficiency (e.g. Fe, Mn, P) $)^{3,22}$ as shown previously ${ }^{22}$. This impact of lightning on biomass production due to effects on biogeochemistry is especially true for ecosystems of the tropics/subtropics ${ }^{23-25}$.

Our measurements and estimates reveal a noticeable impact of lightning activity by galvanic effects on the mobilization of redox sensitive elements such as Fe/Mn on a local scale. Consequently, this process has to be considered in biogeochemical studies and modeling. The described galvanic process may also occur for all other redox sensitive elements (C, N, P, S, Cr, Co, As, Sb, Se, Hg, Tc and U $)^{26}$ and may alter their biogeochemical cycling characteristics.

\section{Methods}

To analyze the impact of galvanic lightning effects on $\mathrm{Mn}$ and Fe remobilization in soils or sediments, experiments were conducted under nature like conditions (sandy soil supernatant rain water to simulate conditions after intense rain). An analytical vessel was connected to a high current pulse generator. The vessel consists of an aluminum $(\mathrm{Al})$ forged tube of $1.5 \mathrm{~cm}$ wall thickness, $35 \mathrm{~cm}$ inner diameter and $70 \mathrm{~cm}$ height. The bottom and top of the vessel were closed with a $2 \mathrm{~cm}$ thick Al-plate. The whole vessel inside was isolated by polyethylene film. A copper cathode (top) and copper anode (bottom) inside the analytical vessel had a distance of $35 \mathrm{~cm}$ and were connected by a thin copper ignition wire. Hence, only less than the half of the volume in the analytical vessel was filled with water and sand and the rest of the vessel served as compensatory volume to absorb the pressure resulting by lightning. This ignition wire enables initial electron flow from cathode to anode. The dimensions of the analytical vessel were chosen to optimize the water and soil volume in relationship to the occurring pressure. In order to conduct the experiments under nature like condition and also prevent destructive electro-hydraulic effects by lightning arcs it was chosen to limit the charging voltage of the condensators to values of about $6 \mathrm{kV}$. Five liters of sand and three liters of water were uniformly distributed on the anode around the ignition wire but with $5 \mathrm{~cm}$ distance to the cathode. The sandy soil originated from a sandpit (Dresden, Germany) was soaked with artificial rain water with $\mathrm{pH}=$ 5.6 and low soluble minerals concentration (Table S1). Prior to the experiment the sand was carefully washed, dried and stored until start of experiments. The sand had a quite low metal content (Table S1). After filling the analytical vessel with soil and water, it was closed and the lightning strikes were conducted at 4 to $6 \mathrm{kV}$ and charges of 0.007 to $32 \mathrm{C}$ within a few microseconds. The lightning currents were delivered by a CLR - current pulse generator. The condensators of the generator are connected in parallel, low- inductive configuration. By charging voltages up to $10 \mathrm{kV}$ it is possible to deliver 10/350 $\mu$ s shaped lightning currents with amplitudes up to $200 \mathrm{kA}$ with this $\operatorname{setup}^{27}$. For conducting positive lightning a reverse electric polarity was used. Water samples were taken randomly five minutes after closing the analytical vessel and conducting the lighting and filtered by cellulose acetate filters (pore diameter $0.45 \mu \mathrm{m}$ ). Then water samples were divided afterwards. One aliquot was immediately analyzed for ferrous iron. The other part was acidified with $\mathrm{HNO}_{3}$ (analytical grade, Carl Roth Germany). For the sand substrate characterization prior to the experiment, it was subjected to an aqua regia extraction according to Ref.28, using a CEM Mars5 microwave digestion system (CEM Corporation, Matthews, NC, USA). The elemental contents of waters and solid sample digests were determined by ICP-MS (PQ exCell instrument, Thermo Fisher Scientific Inc.) according to Ref.29. In addition, the water ferrous iron concentration was analyzed immediately after the experiment according to Ref.30. All chemicals were of analytical grade. Student's $t$-test was applied to compare the data using SPSS 16.01.

The calculations on the chemical elements mobilized by a change in electric charge (galvanic lightning effects) are based on Faraday's laws:

$$
\delta_{\text {mol }} \mathrm{Me}=\frac{\text { Charge of lightning }(\mathrm{C})}{\mathrm{Z}^{*} \text { Faraday constant }}
$$

$\delta_{\text {mol }} \mathrm{Me}$ is the amount of remobilization of a metal and $\mathrm{Z}$ the charge number change. According to the known soil chemical redox pairs $\mathrm{Z}$ is one for the transfer from ferric to ferrous iron, and two for the release of divalent $\mathrm{Mn}$ from $\mathrm{Mn}$-dioxide. C refers to the released charge per lightning event ( $16 \mathrm{C}$ for positive and 5.2 for negative lightning) and the Faraday constant (F) of $96485.3365 \mathrm{C} \mathrm{mol}^{-1}$. For the estimation of the global annual mobilization of $\mathrm{Mn}$ and Fe by reduction due to a shift in energy charge, 30 cloud-ground lightning events per second are chosen ${ }^{19}$. The calculation was done on a hypothetical assuming that all transferred charge is used to reduce $\mathrm{Fe}^{3+}$ to $\mathrm{Fe}^{2+}$ or $\mathrm{Mn}^{4+}$ to $\mathrm{Mn}^{2+}$, because this is the maximum effect depending on redox status or element domination in the affected soils/sediments, for the most abundant redox sensitive metals in natural soils/sediments.

1. Turekian, K. K. \& Wedepohl, K. H. Distribution of the elements in some major units of the earth crust. Geol. Soc. Am. Bull. 72, 175-191 (1961).

2. Loscher, B. M., DeBaar, H. J. W., DeJong, J. T. M., Veth, C. \& Dehairs, F. The distribution of Fe in the Antarctic Circumpolar Current. Deep-Sea Res. Part IITop. Stud. Oceanogr. 44, 143-187 (1997).

3. Schlesinger, W. H. \& Bernhardt, E. S. Biogeochemistry: an analysis of global change. 688 (Academic Press, Waltham, 2013).

4. Rusch, A., Huettel, M., Wild, C. \& Reimers, C. E. Benthic oxygen consumption and organic matter turnover in organic-poor, permeable shelf sands. Aquat. Geochem. 12, 1-19 (2006).

5. VanCappellen, P. \& Gaillard, J. F. in Reactive Transport in Porous Media Vol. 34 Reviews in Mineralogy eds P. C. Lichtner, C. I. Steefel, \& E. H. Oelkers) 335-376 (Mineralogical Soc Amer, 1996).

6. Roden, E. E. \& Edmonds, J. W. Phosphate mobilization in iron-rich anaerobic sediments: Microbial Fe(III) oxide reduction versus iron-sulfide formation. Arch Hydrobiol. 139, 347-378 (1997).

7. Matsunaga, T., Karametaxas, G., Vongunten, H. R. \& Lichtner, P. C. Redox chemistry of iron and manganese minerals in river-recharged aquifers - a model interpretation of a column experiment. Geochim. Cosmochim. Acta 57, 1691-1704 (1993).

8. Chang, Z. S., Yuan, P. \& Guo, Y. X. Transport Coefficients of Lightning Discharge Plasma on Plateau Area in China. IEEE Trans. Plasma Sci. 38, 2048-2051 (2010).

9. Pasek, M. \& Block, K. Lightning-induced reduction of phosphorus oxidation state. Nat. Geosci. 2, 553-556 (2009).

10. Noxon, J. F. Atmospheric nitrogen-fixation by lightning. Geophys. Res. Lett. 3, 463-465 (1976).

11. Sheffer, A. A., Dyar, M. D. \& Sklute, E. C. in 37th Annual Lunar and Planetary Science Conference 2 (League City, 2006), http://www.lpi.usra.edu/meetings/ lpsc2006/pdf/2009.pdf, (accessed 12 June 2013).

12. Wang, J., Yuan, P., Zhang, H. M. \& Shen, X. Z. The study on the characteristics and particle densities of lightning discharge plasma. Spectrosc. Spectr. Anal. 28, 2003-2008 (2008)

13. Soriano, L. R., de Pablo, F. \& Tomas, C. Ten-year study of cloud-to-ground lightning activity in the Iberian Peninsula. J. Atmos. Sol.-Terr. Phys. 67, 1632-1639 (2005).

14. Zajac, B. A. \& Rutledge, S. A. Cloud-to-ground lightning activity in the contiguous United States from 1995 to 1999. Mon. Weather Rev. 129, 999-1019 (2001).

15. Berger, K. \& Vogelsänger, E. Parameters of lightning flashes. Electra 80, 223-237 (1975).

16. Berger, K. Novel observations and lightning discharge - results of research on Mount San Salvatore. J. Frankl. Inst.-Eng. Appl. Math. 283, 478-\& (1967).

17. N.A.S.A. Global lightning pattern: http://earthobservatory.nasa.gov/IOTD/view. php?id=6679. (accessed 14 June 2013).

18. Moore, J. K., Doney, S. C. \& Lindsay, K. Upper ocean ecosystem dynamics and iron cycling in a global three-dimensional model. Glob. Biogeochem. Cycle 18 (2004).

19. Price, C., Penner, J. \& Prather, M. NOx from lightning.1. Global distribution based on lightning physics. J. Geophys. Res.-Atmos. 102, 5929-5941 (1997). 
20. Bogaerts, A., Gijbels, R. \& Carman, R. J. Collisional-radiative model for the sputtered copper atoms and ions in a direct current argon glow discharge. Spectroc. Acta Pt. B-Atom. Spectr. 53, 1679-1703 (1998).

21. Zhuravleva, E. N., Drozdova, T. N., Ponomareva, S. V. \& Kirik, S. D. Iron migration from the anode surface in alumina electrolysis. Appl. Surf. Sci. 265, 790-795 (2013).

22. Chacon, N., Silver, W. L., Dubinsky, E. A. \& Cusack, D. F. Iron reduction and soil phosphorus solubilization in humid tropical forests soils: The roles of labile carbon pools and an electron shuttle compound. Biogeochemistry 78, 67-84 (2006).

23. Blain, S. et al. Effect of natural iron fertilization on carbon sequestration in the Southern Ocean. Nature 446, 1070-U1071 (2007).

24. Ticconi, C. A. \& Abel, S. Short on phosphate: plant surveillance and countermeasures. Trends Plant Sci. 9, 548-555 (2004).

25. Krom, M. D., Kress, N., Brenner, S. \& Gordon, L. I. Phosphorus limitation of primary productivity in the eastern Mediterranean-Sea. Limnol. Oceanogr. 36, 424-432 (1991).

26. Borch, T. et al. Biogeochemical Redox Processes and their Impact on Contaminant Dynamics. Environ. Sci. Technol. 44, 15-23 (2010).

27. González, D. \& Noack, F. in 28th International Conference on Lightning Protection. 1223-1228.

28. DIN-EN-13346. Bestimmung von Spurenelementen und Phosphor, Extraktionsverfahren mit Königswasser. 20 (Beuth Verlag, Berlin, 2001).

29. BS-EN-ISO-17294-2:2004. Water quality. Application of inductively coupled plasma mass spectrometry (ICP-MS). Determination of 62 elements., 30 (ASLIB, London, 2004).

30. Tamura, H., Goto, K., Yotsuyan, T. \& Nagayama, M. Spectrophotometric determination of iron(II) with 1,10-phenanthroline in presence of large amounts of iron(III). Talanta 21, 314-318 (1974).

\section{Acknowledgments}

The authors are grateful to D. González (TU Ilmenau, Germany) for assistance operating the current pulse generator, to VDE Verband der Elektrotechnik Elektronik Informationstechnik e.V. Ausschuss für Blitzschutz und Blitzforschung (Frankfurt am Main, Germany) for funding and to J. Senft (Burg Giebichenstein Kunsthochschule Halle, Germany) for drafting Fig. 3. Furthermore, the authors are grateful to C. Brackhage and L. Paul (both TU Dresden, Germany) for comments on earlier versions of the manuscript and for proof-reading.

\section{Author contributions}

J.S. and A.W. designed the experiment, conducted the experiment and wrote the manuscript. F.B. supplied the lightning laboratory equipment and gave comments to the manuscript. All authors reviewed the manuscript.

\section{Additional information}

Supplementary information accompanies this paper at http://www.nature.com/ scientificreports

Competing financial interests: The authors declare no competing financial interests. How to cite this article: Schaller, J., Weiske, A. \& Berger, F. Thunderbolt in biogeochemistry: galvanic effects of lightning as another source for metal remobilization. Sci. Rep. 3, 3122; DOI:10.1038/srep03122 (2013)

(c) (i) $\odot$ This work is licensed under a Creative Commons Attribution-

NonCommercial-NoDerivs 3.0 Unported license. To view a copy of this license, visit http://creativecommons.org/licenses/by-nc-nd/3.0 